This is the post-peer reviewed final draft version of the following article: Heeks, R. "eGovernment in Africa: promise and practice", Information Polity, 7(2-3), 97-114, 2003, which has been published in final form at:

http://iospress.metapress.com/content/4hgua3eglj7gdlv3/

\title{
eGovernment in Africa: Promise and Practice
}

\author{
Richard Heeks \\ Institute for Development Policy and Management \\ University of Manchester \\ Precinct Centre \\ Manchester M13 9GH \\ UK \\ Phone: +44-161-275-2870 \\ Fax: +44-161-273-8829 \\ Email: richard.heeks@man.ac.uk
}

\begin{abstract}
eGovernment has already arrived in Africa, though it is essentially an imported concept based on imported designs. There are growing numbers of e-government projects, some of which are contributing to public sector reform and delivering gains of efficiency and/or effectiveness across a broad agenda. However, this positive picture must be set alongside significant challenges. eGovernment is only slowly diffusing within Africa because of a lack of 'e-readiness for e-government' that can be charted along six dimensions. There is widespread recognition that this challenge must be met by strategic building of national infrastructure. Where e-government projects are introduced, they mainly end in failure; either partial or total. To address this tactical challenge, stakeholders must be sensitised to the large gaps that often exist between project design and African public sector reality. These large 'designreality gaps' can be seen to underlie failure. They arise particularly because egovernment concepts and designs have their origins in the West; origins that are significantly different from African realities. Some best practices are outlined that may help to close design - reality gaps and, hence, may help to improve project success rates. This will only happen, though, if they too are appropriate to African realities.
\end{abstract}




\section{Introduction: African Governance - 'Crisis' and Solutions}

There is a widespread sentiment that systems of governance in Africa are in crisis. In a functionalist sense, perceived problems of the public sector focus on (drawn from Adeboye 1995, Olowu 1999, Castells 2000):

- Inputs. In a number of countries, the public sector is seen to require unsustainably large and/or unsustainably increasing public expenditure; with a looming threat or reality of heavy public debt.

- Processes. There is concern about examples of waste, delay, mismanagement and corruption within the public sector, all of which contribute to inefficiency in the conversion of public expenditure into public services.

- Outputs. Concerns are widespread in a number of countries that the public sector is not delivering what it should, from adequate defence and policing through support for agriculture and industry to education, housing, health, social welfare and a hundred other responsibilities. This, in turn, undermines the wider social outcomes of public sector activity.

The perception of difficulties covers both what the African public sector is doing (the public sector's role) and also how it is doing it (public sector organisation and management).

There is debate on whether this crisis is real or manufactured, absolute or only relative to potentially-inappropriate Western models of governance (Kruiter 1996). However, we must skirt that debate and focus, instead, on the reality of perceptions and the consequent reality of a perceived need for solutions to the 'crisis'.

As in so much of Africa's recent history, a source of claimed solutions lies outside the continent. New public management (NPM), with its origins in Western countries and Western neo-liberalism, has been pushed by Western donors as the dominant programme for change in the African public sector: "the most recent in a long line of policy transfers and modernizing exchanges between North and South in the last half century." (Minogue 2001:1; see also Common 1998).

eGovernment - whether seen as a component of NPM or an extension of NPM - is but the latest example of such transfers: a more appropriate term than "exchanges", which suggests an equality of interaction between industrialised and developing countries that does not exist. The carriers for this transfer of ideas are four main groups (Common 1998, Korac-Kakabadse et al. 2000, Therkildsen 2000):

- International donor agencies. These have been a main channel for the transfer of new public management through their good governance agendas. These agendas are now incorporating and transferring the e-government message. The donors, providing a significant proportion of the income for government in many African countries, create powerful leverage for e-government.

- Consultants. Consultants work within African governments for many reasons: to compensate for weak or absent skills; to legitimise pre-determined changes; as a required component of donor-funded change. They form an important component that both drives and shapes the reform agenda, including the e-government agenda within Africa.

- Information technology (IT) vendors. Worldwide, there is an inequality of knowledge, of skills, of experience between IT vendors and their public sector 
clients, with the former seen as possessing more of these important resources.

Such inequalities are particularly acute in Africa where the often-painted picture of 'virgins marrying Casanova' fits perfectly the imbalanced interactions that occur between public servants and vendors. As such, the vendors are often in a position to guide - even dictate - the direction and content of e-government.

- Western-trained civil servants. As discussed further below, many middle and senior civil servants in Africa receive a Western education. This education can play an influential role in exposing those staff to Western ideas about new public management, and about e-government.

In sum, e-government, like NPM, is an imported concept but one that is now an increasing element of reform programmes in Africa. With this in mind, we now move on to look at the potential contribution that e-government can make.

\section{A. eGovernment's Contribution to Reform in Africa}

African governments have been using information technology for more than 40 years: e-government before it was called e-government. eGovernment should thus be seen as evolutionary, not revolutionary. Nonetheless, we can make a simplistic contrast between:

- The old model: information technology automating the internal workings of government by processing data.

- The new model: information and communication technologies (ICTs) supporting and transforming the external workings of government by processing and communicating data.

eGovernment should be seen to encompass all ICTs in all activities of the public sector, but the key innovation is computer networks - from intranets to the Internet creating a wealth of new digital connections, as summarised in Figure 1 (adapted from Ntiro 2000).

\section{Figure 1: Focal Domains for eGovernment Initiatives}

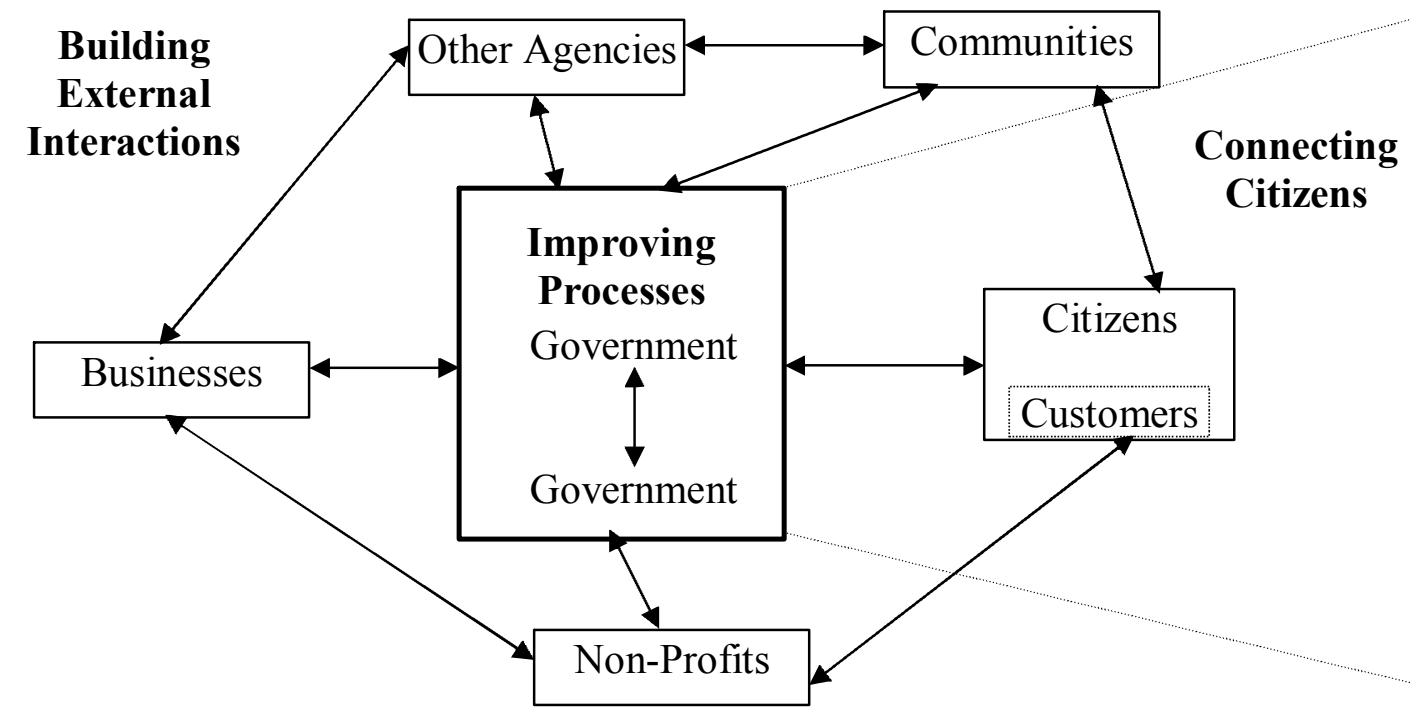


Each of the three main domains will now be discussed in greater detail.

\section{A1. Improving Processes: eAdministration}

eGovernment initiatives within this domain deal particularly with improving the internal workings of the public sector. They include:

- Cutting process costs: improving the input:output ratio by cutting financial costs and/or time costs.

- Managing process performance: planning, monitoring and controlling the performance of process resources (human, financial and other).

- Making strategic connections in government: connecting arms, agencies, levels and data stores of government to strengthen capacity to investigate, develop and implement the strategy and policy that guides government processes.

- Creating empowerment: transferring power, authority and resources for processes from their existing locus to new locations.

An example of an e-administration application in Africa, related to making strategic connections in government, is given in Box 1.

\section{Box 1 \\ Supporting Reform of Customs Tariffs in Egypt}

(Kamel 1998)

"Through one of its reform programmes, the Cabinet was about to impose a new set of customs tariffs, largely for imported goods, which were intended to reduce the burden on low income groups, increase the revenue of the government, and create a homogeneous and consistent tariff structure. Anticipation of the tariff changes caused stagnation in the business sector for four months. As a result, multi-sectoral conflicts arose between six different ministries. Hence, some form of decision support system was needed to resolve the conflict and to support imposition of the new tariffs. Therefore, a team consisting of Ministry of Finance and IDSC [Information and Decision Support Centre] personnel was formed to interact with the different parties, get feedback and generate different scenarios to be assessed. A computerised DSS was developed, as a result of which the various inter-ministerial conflicts were resolved within a four-week period. Moreover, a tariff structure was formulated, based on the various scenarios and alternatives that were generated by the decision support system. The government endorsed the new tariff model which was also accepted by the business sector."

The example cited in Box 1 is somewhat unusual. Traditionally, as in the industrialised countries, ICTs in Africa have been used within government in 'automation' mode, replacing clerical labour processes with their digital equivalent. These are essential building blocks for e-government, and they have often been introduced with a rationale of cutting costs (Mulira 1995, Oyomno 1996). 
However, their achievement of financial cost-cutting goals is questionable. In industrialised countries, replacing costly civil servants with cheap ICTs may cut costs, though even here evidence of efficiency gains is limited (e.g. Henman 1996, OMB 2002). In Africa, average public sector wage costs can be one-tenth or less than those in the West (Ayittey 1998, Teal 2000); average ICT costs can be two to three times higher (Heeks and Kenny 2002). eGovernment automation therefore means replacing cheap civil servants with costly ICTs: something that is most unlikely to be justified on financial cost grounds.

As time replaces money as a more critical global resource, ICTs' ability to increase process speed may provide some justification for automation. More generally, though, ICTs need to be justified and understood in the context of a broader vision and necessity for e-government in Africa.

\section{A2. Connecting Citizens: eCitizens and eServices}

Such initiatives deal particularly with the relationship between government and citizens: either as voters/stakeholders from whom the African public sector should derive its legitimacy, or as customers who consume public services. These initiatives may well incorporate the process improvements identified in section A1. However, they also include a broader remit:

- Talking to citizens: providing citizens with details of public sector activities. This mainly relates to certain types of accountability: making public servants more accountable for their decisions and actions.

- Listening to citizens: increasing the input of citizens into public sector decisions and actions. This could be flagged as either democratisation or participation.

- Improving public services: improving the services delivered to members of the public along dimensions such as quality, convenience and cost.

An example of an e-citizen application in Africa, related to listening to citizens, is given in Box 2.

\section{Box 2 \\ Supporting Free and Fair Elections in South Africa}

(Microsoft 2000)

Following difficulties in the 1994 elections, South Africa's Independent Electoral Commission "was charged with making sure that the country's second democratic elections in 1999 were 'free and fair'. This election was vitally important for the stability of the South African political climate and for ensuring that democratic processes were solidly in place. Through large scale implementation of unique information technology applications, the IEC was able to ensure that all South African citizens could have their voices heard. The effort included the creation of a nationwide satellite-based wide-area network and infrastructure; a bar-code system used to register 18.4 million voters in just nine days; a geographic information system used to create voting districts; a national common voters' role; a sophisticated election results centre for managing the process; and the training of 300,000 people. The 
massive programme was completed in less than two years, in time for the vote." For this, the IEC received the 2000 Computerworld Smithsonian Award for most outstanding programme in the government and non-profit organisations category.

One key aim of e-government in this domain has been disintermediation (Heeks forthcoming). For example, by publishing forms on the Web, e-government initiatives can potentially cut out the public servants and others who may illegally charge citizens for access to such forms.

However, the model for disintermediation in Africa will not match that in the West. In the West, the main models for government - citizen interaction have been disintermediated models of direct digital connections to the individual citizen (e.g. Cabinet Office 2000). In other words, these are models involving the replacement of human intermediaries by ICT intermediaries. For the majority of those citizens in industrialised countries who interact digitally with government, the ICT intermediary is personally-owned (typically an Internet-linked PC in the home or workplace). For many others, the ICT intermediary is institutionally-owned (typically in a local community centre, library, school, post office, telecentre, etc.).

In Africa, the first model - citizen direct ownership and use of ICTs - will apply to only a small fraction of the population for the foreseeable future (Pyramid Research 2000). A greater number will gain access through the second model - non-ownership but direct use of ICTs - through similar institutions to those listed above. Many will also fall into the grey area between these models that is particularly found in Africa direct use of ICTs owned by family, friends, neighbours or colleagues.

Nevertheless, for the medium-term, the majority of citizens will remain on the wrong side of the digital divide. They create a substantial need for a third model - of those who are neither direct owners nor direct users of ICTs. To benefit from egovernment, these citizens will have to rely on reintermediation models that insert a human intermediary between the citizen and the growing digital infrastructure of egovernment (Wilson and Heeks 2000). Where institutionally based, these can be thought of as 'intelligent intermediaries' that add human skills and knowledge to the presence of ICTs.

Realistic e-government projects in Africa will therefore have to identify and nurture such intermediaries. They may be existing professionals (e.g. accountants for online tax systems; notaries for online registration systems); or public servants (e.g. in call centres or in one-stop-shop government offices); or NGOs and community-based organisations (e.g. staffed community telecentres); or private sector organisations (e.g. cybercafes); or other public institutions.

\section{A3. Building External Interactions: eSociety}

Such initiatives deal particularly with the relationship between public agencies and other institutions - other public agencies, private sector companies, non-profit and community organisations - and with the relationship between civil society institutions. As with citizen connections, these initiatives may well incorporate the 
process improvements identified in section A1. However, they also include a broader remit:

- Working better with business: improving the interaction between government and business. This includes digitising procurement from and services to business to improve their quality, convenience and cost.

- Developing communities: building the social and economic capacities and capital of local communities.

- Building partnerships: strengthening institutional relationships. This has two parts. First, building government partnerships: strengthening relations between government and other institutions such as NGOs or international organisations. Second, building civil society partnerships: strengthening relations between the institutions of civil society, such as between NGOs.

An example of an e-society application in Africa, related to working better with business, is given in Box 3.

Single Point Tax Payments in Mauritius
(Lollbeharree and Unuth 2001 plus author fieldwork in Mauritius)
The Contributions Network Project (CNP) is a public-private partnership initiative
that provides a single channel for all payments Mauritian firms need to make to
various government departments. To date, several hundred large firms have joined
the system, which allows either EDI (Electronic Data Interchange)- or Web-based
reporting of both income and value-added tax dues. The firm's report is automatically
broken down, with relevant components sent to relevant government departments. An
order for electronic funds transfer is also automatically generated, moving funds from
company to government accounts. The scheme has reduced time and labour
requirements for both firms and government departments. It has also reduced
reporting and processing errors, due to built-in validation checks within the electronic
reports, removal of the need to re-enter data, and automatic reconciliation of detailed
figures with totals. Firms can now pay closer to the deadline, and cash flow for
government has been improved with a reduction in payment arrears.

eSociety - at least relating to communities or to other non-governmental institutions has been a focus for recent donor-funded 'e-development' initiatives in Africa (Heeks 2001). Why? Partly because such initiatives operate at the institutional rather than individual level, and because they operate somewhat independently of the red tape of government. There has also been a strong e-development interest in governmentdisintermediating service delivery initiatives. These seek to deliver education and health advisory and other information-intensive services direct without state intervention, often on a global basis from the West to Africa.

Other components of e-society - typically those relating to government links - have been rather more neglected. Thus, as with citizen-focused projects, the opportunity has yet to be fully grasped to use the new connectivity to help refocus African states from an internal, self-serving view to an external, nation-serving view. 


\section{B. Challenges to eGovernment in Africa}

The boxed success stories cited above are the exception rather than the rule for two reasons. First, most African countries have undertaken only a limited number of egovernment projects. Second, most African e-government projects fail in some way. Both of these challenges are now discussed in greater detail.

\section{B1. Slow Diffusion of eGovernment in Africa}

African governments have fewer e-government initiatives than industrialised countries; make less use of ICTs in their work than industrialised countries; and use older generations of technology than industrialised countries (Zammit 2000, West 2001).

Why should this be?

Of course a major explanation is financial. African governments have far less money in both absolute and per capita terms to spend on ICTs than Western governments. Both related and additional to this issue is the greater lack of strategic "e-readiness for e-government" in Africa.

eReadiness has become sufficiently widespread as a concept to spawn a number of variants (CID 2000, Bridges.org 2001, McConnell International 2001, PCIP 2002). From these variants, we can tease six factors that are of main relevance to egovernment in Africa. These can be posed as an inventory of "e-readiness for egovernment" questions.

a. Is the data systems infrastructure ready: are the management systems, data standards, records and work processes in place to provide the quantity and quality of data to support the move to e-government? In many African countries, data quality and data security - for example - are very poor, and there are few mechanisms to address these issues (Cain 2001).

b. Is the legal infrastructure ready: are the laws and regulations required to permit and to support the move to e-government in place? In most African countries, for example, digital signatures cannot be accepted (Garfinkel 2001).

c. Is the institutional infrastructure ready: e-government can only progress if the institutions exist to act as a focus for awareness and to act as a means for facilitation of e-government. In most African countries, there are no institutions to co-ordinate and lead and drive e-governance (Korac-Kakabadse et al 2000).

d. Is the human infrastructure ready: are the attitudes, knowledge and skills in place - especially within the public sector - that are required to initiate, implement and sustain e-government initiatives? In many African countries, key skills gaps relate to business analysis and system design, and to project management, contract management and vendor management (Mundy et al 2001). There are also 'mindset' 
gaps: general resistance to change; lack of customer-orientation; resistance to datasharing; etc.

e. Is the technological infrastructure ready: although there have been great strides forward, the fact remains that most African countries are a long way short of the computing and telecommunications infrastructure on which many Western egovernment initiatives have been based (ITU 2002).

f. Is the leadership and strategic thinking ready: a critical pre-condition in successful e-government is an e-champion or small group of e-champions: leaders with vision who put e-government onto the agenda, who set e-government within a broader reform agenda, and who make it happen. Of all the e-readiness issues, this is probably the most critical (PCIP 2002). Hence, the limited number of senior officials who feel willing or able to champion ICTs in government in Africa acts as a most serious constraint to e-government diffusion (Udo and Edoho 2000).

\section{B2. High Failure of eGovernment in Africa}

The six areas of e-readiness just identified represent the strategic challenge to egovernment in Africa. They operate at the macro-level of the whole nation, and they act as a precursor to e-government. As discussed later, they have also been relatively well recognised and discussed.

In addition, though, there is the less-heralded but potentially more significant tactical challenge that faces the micro-level of individual e-government projects during their implementation. This is the challenge of avoiding failure and achieving success. The significance of this challenge can be seen in the high incidence of failure within African e-government projects. In analysing case studies of such projects, three dominant categories of reported outcome emerge, as they would for analysis of any set of ICT projects.

First, there is the total failure of an initiative never implemented or in which a new system is implemented but immediately abandoned. For example, a land licensing information system was introduced by a municipal government in Southern Africa (Anonymous 2000). The system was never used, largely because it conflicted with the entrenched interests of powerful groups who used land licensing for their own gain.

A second possible outcome is the partial failure of an initiative in which major goals are unattained or in which there are significant undesirable outcomes. This includes the 'sustainability failure' of an initiative that at first succeeds but is then abandoned after a year or so. An example is the creation by central government of a set of touchscreen kiosks for remote rural communities in South Africa's North-West Province (Benjamin 2001). These were initially well received by the communities. However, the kiosks' lack of updated or local content and lack of interactivity led to disuse, and they were removed less than one year later.

This category also includes the 'zero-sum failure' of an initiative that succeeds for one stakeholder group but fails for another. This occurred during the Accounts and 
Personnel Computerisation Project of Ghana's Volta River Authority. Most managerial staff in the finance department were pleased with the changes brought by the new system. However, the implementation "bred a feeling of resentment, bitterness and alienation" among some lower-level staff, and led to resistance and non-use, particularly among older workers (Tettey 2000:72).

Finally, one may see the success of an initiative in which most stakeholder groups attain their major goals and do not experience significant undesirable outcomes. Examples of this were given in the boxed cases above.

Estimating the proportion of African e-government projects that falls into each category is not easy. Setting aside issues of categorisation per se, the greatest barrier is the lack of evidence. Even aid donors, who should be committed to monitoring and evaluation, rarely seem to produce reports.

Despite these limitations, there are some glimpses of evidence. Two overviews of ICT projects in African government conclude:

- "Information systems fail or underperform more often than they succeed in the public sector in Africa" (Peterson 1998:38).

- "The success rate of introduced information technology systems in African state agencies has been distressingly low" (Berman and Tettey 2001:2).

A few more specific multiple-case studies have been conducted, with examples summarised below:

- World Bank-funded public sector ICT projects in Africa: almost all were partial often sustainability - failures (Moussa and Schware 1992).

- Use of ICTs for health reform in South Africa's public sector: there was widespread partial failure of high cost systems with little use of data (Braa and Hedberg 2000).

- ICT-based personnel information systems in three African government: all three failed to achieve their stated objectives and were thus partial failures (Cain 2001).

- eGovernment projects in Africa: two of the eleven surveyed were total failures, nine were partial failures, and none were successes (Heeks 2002).

Likewise, reports on ICT use in the public sectors of individual African countries find failure to be the dominant theme (Oyomno 1996, Peterson 1998).

It is important to acknowledge that African countries are not alone in suffering egovernment failures, and to acknowledge that the evidence base is not strong (and that it urgently needs strengthening). However, the evidence does all point in one direction: towards high rates of e-government project failure in Africa.

\section{Understanding Success and Failure of African eGovernment}

If this is so, we should seek to understand why. That is the intention of this section to develop and then apply a model that helps explain why so many African egovernment projects fail.

There have been few, if any, analytical studies of e-government success and failure in Africa. In seeking models, we therefore turn initially to the broader literature on success and failure of ICT projects in developing countries. 
This writing has tended to fall into one of two camps. The first, and larger, camp may be described as 'factoral analysis'. Taking either a case or a survey of cases, this literature focuses on categorising the factors that constrain implementation of ICTs in developing countries (e.g. Matta and Boutros 1989; Boon 1992; Beeharry and Schneider 1996). This literature has been useful in helping build the overall body of knowledge. However, there have been shortcomings. Many writings have tended to focus "on conditions rather than actions and behaviors, and on weaknesses rather than on ways of overcoming them" (Montealegre 1999:201). Where there are actionoriented recommendations, they have often been normative and prescriptive. They have also been fragile, lacking the theoretical underpinnings or even models that would permit generalisation with confidence.

At the other end of the spectrum has been a smaller camp of work attempting much needed theory building; typically from the base of Gidden's structuration theory or Callon's/Latour's actor network theory (e.g. Baruah 2000; Barrett et al 2001). The main audience for such work has been information systems academics. Only individual cases have been produced, and implications have often been hard to divine for those struggling at the coal-face of e-government failure.

This paper attempts to steer a 'third way' between the two camps, developing a general framework on the basis of multiple case studies, but a framework that provides some direct operational recommendations. Such explanatory frameworks of IS success and failure have already been offered in the literature (e.g. Horton and Lewis 1991; Sauer 1993). What follows is one particular approach, developed from soft systems ideas (e.g. Checkland 1981).

The starting point - a reaction against the normative assumptions of some previous literature - is the classic contingency model (Lawrence and Lorsch 1967; Poulymenakou and Holmes 1996). Contingency sees no single blueprint for success and failure in organisational change. Instead, it recognises that there are situationspecific factors for each e-government project which will determine success and failure and, hence, strategies for success.

Inherent within most ideas of contingency is the idea of adaptation: of states of mismatch and match between and within factors and of the need to change in order to adapt systems so that there is more match than mismatch. In the context of overall organisational change, this is mainly described in terms of the need for adaptation of organisational structure to the organisational environment (Butler 1991). In the context of African e-government projects, too, there is an 'environment' to which the e-government system can be adapted.

This environment - and the e-government initiatives themselves - incorporate not just technological but also social and organisational factors. The critical role played by these latter factors in the implementation of ICTs in developing countries has been noted many times (e.g. Bada 2000; Salazar 2001). In turn, these social and organisational factors are not just a question of relatively objective realities, such as work processes or organisational structures, but also of relatively subjective perceptions and values. These perceptions and values plus other assumptions about processes, structures, etc. are not merely expressed in debate during e-government 
implementation; they also come to be inscribed into the design of e-government systems used in Africa (Braa and Hedberg 2000).

Returning to ideas of contingency and adaptation, we can therefore conclude that a successful African e-government system will be one that tends to match its environment in relation to technical, social and organisational factors; these latter including the values, perceptions and assumptions of key stakeholders.

However, there is a major problem here: if the e-government system were to exactly match its environment, it would not change that environment in any way. Yet the formal purpose of such systems is to support and bring about organisational change in order to improve the functioning of the African public sector. There must therefore be some degree of change that an e-government system introduces. Indeed, a greater degree of change may bring greater organisational improvements (though there is no necessary link between size of change and size of benefits).

On the other hand, the greater the degree of change, the greater the risk of failure (Dodd and Fortune 1995, Sauer 1999). For example, the previously-cited World Bank survey of African public sector ICT projects found it was the 'ambitious or complex' ones that were most likely to fail; to be feasible, projects had to be 'modest' about the amount of change involved (Moussa and Schware 1992).

Overall, then, there is a trade-off between change and risk for an e-government project. Reducing the degree of change may increase the likelihood of success, but also reduce the organisational benefits. Conversely, increasing the degree of change may reduce the likelihood of success but also increase the organisational benefits if the change is successful. This trade-off will be felt particularly sharply in Africa. On the one hand, the opportunity costs of failure are high because of the more limited availability of resources such as capital and skilled labour. On the other hand, the pressure for change and benefits is high because only successful projects will bring any hope of reducing the currently growing inequalities between Africa and the West (Kenny 2001).

Putting all these ideas together, we see that central to African e-government project success and failure is the amount of change between 'where we are now' and 'where the e-government system wants to get us'. The former will be represented by the current realities of the particular context (part of which may encompass subjective perceptions of reality). The latter will be represented by the model or conceptions, requirements and assumptions that have been incorporated/inscribed into the new egovernment system's design. Putting this a little more concisely, then, we can say that success and failure depend on the size of gap that exists between 'current realities' and 'design conceptions of the e-government system'.

To illustrate this model, we can use Seyoum's (2002) description of a scientific information system intended to support strategic decision making in a Ministry of Fisheries in East Africa. There were gaps between system design and Ministry reality, along dimensions including:

- An information dimension: the system design assumed that its creation of formal strategic information would be of value to Ministry functioning. In reality, informal information and gut feelings were what decision makers valued and used. 
- A process dimension: the system design assumed that a rationalist model of structured decision-making held sway within the Ministry. This mismatched the dominant reality of personalised, even politicised, unstructured decision-making.

- An objectives and values dimension: the system was designed within, and reflecting, a scientific environment which had a 'role culture' that valued rules and logic. In reality, it was to be used in a political environment which had a 'power culture' that valued self-interest and hidden agendas.

- A management systems and structures dimension: the system was designed for an organisation that had both structures and systems to support strategic decision making. In reality, such structures and systems did not exist within the Ministry. All of this means that there were significant design - reality gaps. The result was failure: the system produced information, but this information was ignored by decision makers.

This shows how the model can be applied to e-government failure in Africa. By contrast, Benjamin (2001) describes the introduction of an intranet in Johannesburg Metropolitan Council. In this case, design and reality were often well matched, along dimensions including:

- An information dimension: the intranet was designed to provide just the kind of information that Council users wanted, creating little gap between designed and actual information needs.

- A technology dimension: the project plan relied mainly on existing technology within the Council, creating little gap between designed and actual technology.

- An objectives and values dimension: the project met the real (sometimes personal) political aspirations of senior councillors and officials, and gained their support, creating little gap between designed and actual objectives.

- A staffing and skills dimension: intranet developers had the necessary skills to produce the system that had been designed, creating little gap between designed and actual skill requirements.

- An other resources dimension: the project was set up cheaply and incrementally, without particular time pressures, creating little gap between designed and actual resource requirements.

All of this meant only limited gaps between e-government project design and Council reality. The result was success. Council processes became more inclusive and transparent. The project was then extended to encompass local community leaders as well.

Analysis of these and other African e-government cases builds seven dimensions of relevance to design - reality gaps: information (data stores, data flows, etc.); technology (both hardware and software); processes (the activities of users and others); objectives and values (the key dimension, through which factors such as culture and politics are manifest); staffing and skills (both the quantitative and qualitative aspects of competencies); management systems and structures; and other resources (particularly time and money).

The design - reality gap model can therefore be summarised, as shown in Figure 2. For each of the seven dimensions, the gap between design and reality can be assessed and rated (e.g. low, medium, high). Overall ratings will give a sense of mismatch between design and reality and, hence, a view of the likelihood of success or failure for the e-government project. 
Figure 2: Design—Reality Gaps in African eGovernment Projects
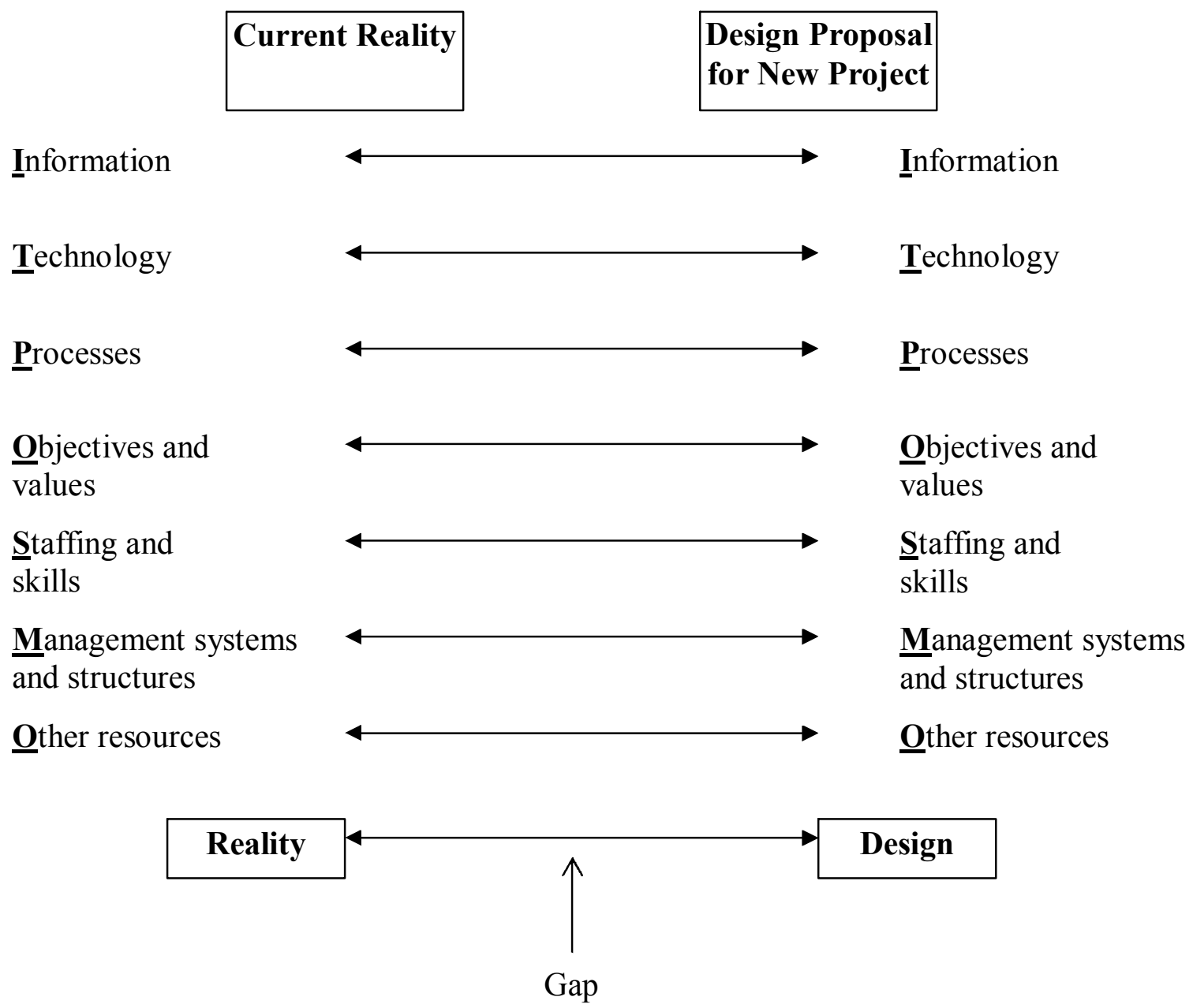

\section{An Archetype of eGovernment Failure in Africa}

There are many ways in which design — reality gaps can affect African e-government projects. However, gaps will arise especially when designs and dominant design stakeholders are remote (physically or psychologically) from the context of egovernment implementation and use. This can happen in a number of ways, but - as noted above in the introduction - the domain of African e-government is particularly dominated by the transfer of Western (i.e. industrialised country) designs to African realities. eGovernment in Africa lies at the intersection of several powerful trends of transfer (Raffer and Singer 1996, Minogue 2001, Heeks and Kenny 2002):

- The channelling of new public management from the West to Africa.

- The economics of innovation and the domination of ICT-related R\&D systems by Western companies and Western researchers.

- The economics and politics of aid, which has been dominated by a flow of resources and artefacts from the West to Africa rather than, for instance, between African nations. 
Risks arise because the contexts of industrialised and of African countries differ in various ways that can be summarised using the ITPOSMO checklist. The list is drawn from findings presented above and from research literature on ICTs in Africa (Lind 1991, Ojo 1992, Woherem 1993, Haque 1996, and Berman and Tettey 2001):

- Information: formal, quantitative information stored outside the human mind is valued less in African countries than in the West.

- Technology: the technological infrastructure (telecommunications, networks, electricity) is more limited and/or older in Africa.

- Processes: work and decision-making processes are more contingent in African governments because of the more politicised and uncertain environment.

- Objectives and values: African public sector organisations are reportedly more likely to have cultures that value kin loyalty, authority, patron-client relations, holism, secrecy, and risk aversion.

- Staffing and skills: African governments have a more limited local skills base in a wide range of skills. This includes information systems skills of systems analysis and design, implementation skills, and operation-related skills including computer literacy and familiarity with the Western languages that dominate computing. It also includes a set of broader skills covering the planning, implementation and management of e-government initiatives; and a yet broader skill set related to analytical and decision-making capacities of the bureaucracy.

- Management systems and structures: African public sector organisations are more hierarchical and more centralised.

- Other resources: African countries have less money. In addition, as noted above, the cost of ICTs is higher than in industrialised countries whereas the cost of labour is less.

Of course, these are stereotypes. One can find many cases in which they are reversed, and one can equally find vast gulfs within industrialised countries. Nonetheless, these differences are real, and partly the legacy of differences between the home and overseas bureaucracies created by the colonial powers (Berman and Tettey 2001). Thus, there are frequent clashes of context between Western design and African public sector reality that can occur in a number of ways.

The most obvious happens when Western stakeholders, such as consultants or IT vendors or aid donors, dominate the e-government design process in Africa. Those stakeholders often bring with them the "If it works for us, it'll work for you" mentality (Odedra-Straub 1995). They also bring their context with them and then impose a design derived from that context that mismatches African realities.

Problems can even occur where stakeholders from industrialised countries are not directly involved, because the West is not just a physical location, it is also a state of mind that has now come to exist for increasing numbers of key figures in African public sectors. This transfer of context occurs directly through education in the West or even in Western-developed educational systems, and indirectly through the leverage gained by Western domination of economic, political and cultural resources and channels. These individuals therefore act as Trojan horses, devising Westerninspired designs within African organisations.

An example of country context gaps is seen in the automation of customs data in Ghana, which used a system developed by Geneva-based UNCTAD with some 
assistance from Western-educated Ghanaians. The system was "developed with assumptions which are embedded in a Western culture of compliance and rationality that is different from that obtaining in Ghana." (Tettey 1997:355). Although the system has automated some processes, it has failed to achieve many of its objectives. Only a "tiny minority" of departments within the Customs and Excise Service use it; it has not prevented continuing tax evasion and fraud; it is perceived negatively by the majority of staff; and its sustainability is open to doubt.

\section{Conclusions}

eGovernment has already arrived in most African countries, and the number of egovernment projects is growing apace, albeit driven significantly by external stakeholders and an external agenda. The cases analysed in this paper show that egovernment has a key role to play in Africa's current and future development. It can offer critical improvements to the efficiency and effectiveness of government; and probably offers critical future legitimacy for government. eGovernment delays in Africa as the West pushes ahead will only reinforce historical patterns of inequality. The issue for African nations, therefore, is not 'if e-government' but 'how egovernment'.

In addressing the 'how', this paper has shown that there must be both a strategic and a tactical response to the current problems for e-government in Africa if improvements and legitimacy are to be delivered.

The strategic response arguably needs to be a generic one, at least in its broad outline; one that addresses all of the key 'e-readiness for e-government' questions posed above. Certainly, it is this generic approach that has been adopted by key international agencies involved with African e-government (such as the DOTForce, the UN ICT Task Force, the World Bank, and others) and, hence, by the growing number of African governments producing e-government-related policies and strategies. The currently-favoured generic strategic response is summarised in Figure 3 (see also Heeks 2001b).

Figure 3: The Strategic Response to Africa's eGovernment Divide

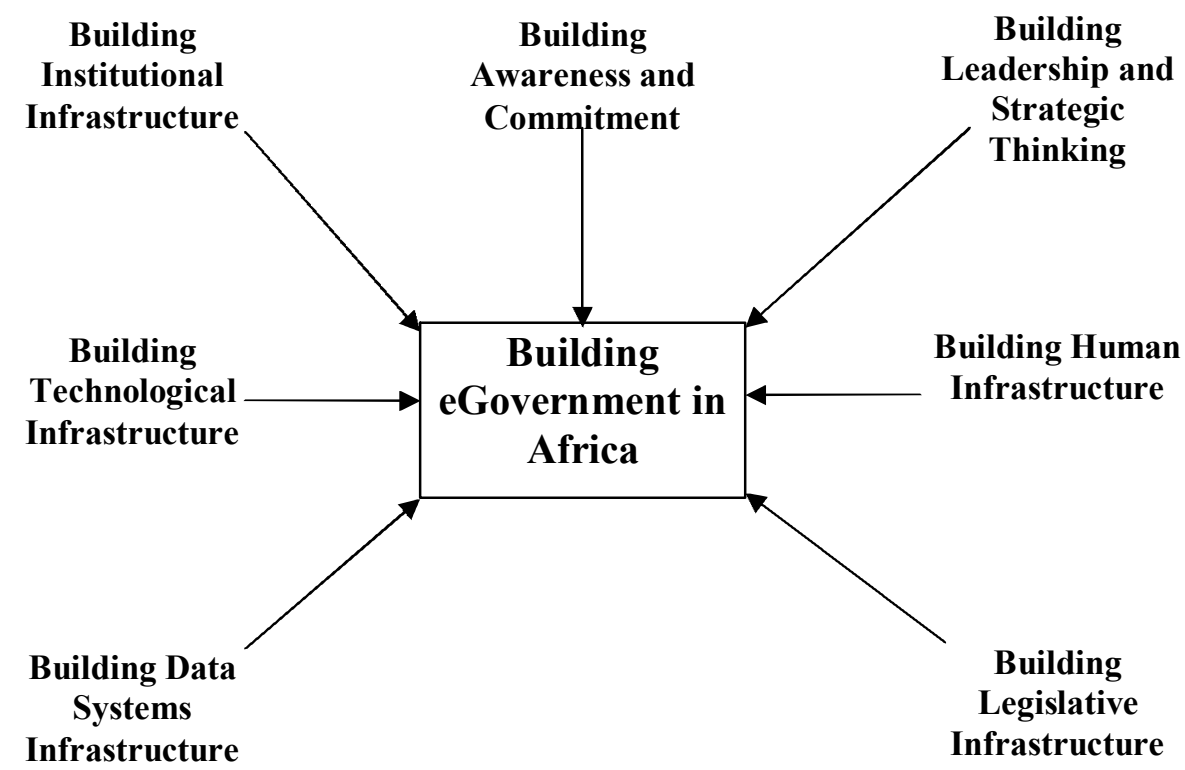


Analysis of agency approaches shows the broad framework of this response is generally agreed by a wide range of commentators. The main discussion about the strategic-level response relates to the detail of, and constraints to, implementation of strategy.

More contentious will be the response to e-government challenges at the tactical level of individual e-government projects. The design-reality gap model presented above challenges the current practices of many key players; especially donor agencies, consultants, and IT vendors. It also challenges the behaviour of African civil servants who - wittingly or unwittingly - are complicit in the continuing importation of inappropriate, Western e-government models and systems. Unless those challenges can be addressed, failure will unfortunately remain the dominant theme for egovernment in Africa.

On the basis of the model presented in this paper, it is argued that the challenges could be addressed through adoption of identified best practice in design - reality gap closure. The most obvious best practice will be customisation to match African realities. As described above, e-government solutions designed for one sector or country are being forced directly into a very different reality, creating failure. To combat this, leaders of African e-government projects must be competent enough and confident enough to demand designs that match their situation's unique reality. The keywords for such projects must be 'customised' not 'off-the-shelf'; 'adapt' not just 'adopt'.

Other examples of gap closure best practice include (Heeks forthcoming):

- Legitimising and mapping current reality: integral to e-government project success is an understanding of reality. Yet this may be difficult to achieve. eGovernment project leaders in Africa can help by 'legitimising reality': by encouraging stakeholders to articulate the difference between rational, prescriptive models of what they should be doing and real depictions of what they are actually doing. Techniques for exposing and mapping organisational realities play a role here. Self- and third party observation helps expose realities. Use of soft systems tools such as rich pictures helps map realities (Checkland and Scholes 1990).

Prototyping helps both, particularly helping users to understand their real information needs.

- Modularity and incrementalism: with the growth in connectivity and as a natural consequence of dealing with millions of entities, e-government projects are frequently large. With pressures from donors/vendors and pressures to play catchup with the private sector or with the West, e-government projects in Africa are frequently ambitious. But, the bigger and bolder the project, the greater the risk of failure. Designers must reconfigure such projects to limit the extent of change at any given time. Stretching project time horizons is one technique. There is also a growing consensus behind modularity (supporting one business function at a time) 
and incrementalism (providing stepped levels of support for business functions) within e-government projects.

- eGovernment hybrids: the need to close design - reality gaps has human resource implications. The gulf between IT professionals and 'mainstream' public servants/politicians is one root cause of design - reality gaps and, hence, of failure in African e-government projects (Peterson 1998, Mundy et al 2001). Successful projects are those where key stakeholders cross this gulf by being 'hybrids' (see Figure 4): those who understand the technology and the business of government and the role of information in government (Heeks forthcoming).

\section{Figure 4: Hybrids for eGovernment Projects}

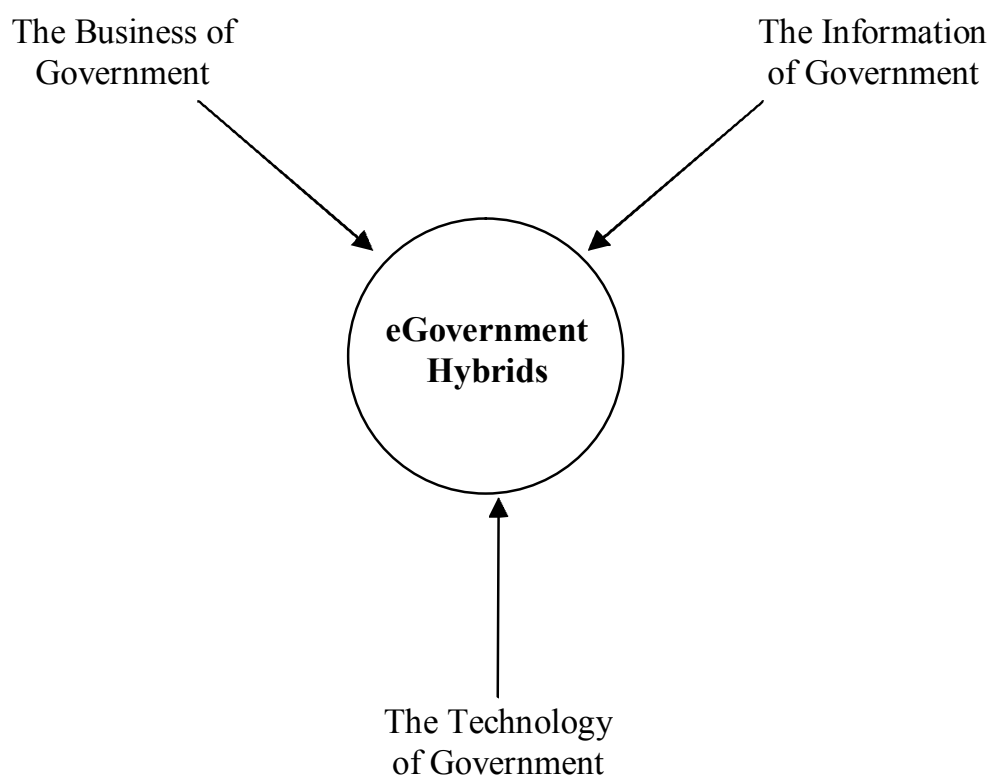

The African e-government hybrid should not be thought of as a single entity. For example, IT professionals for e-government need to be hybridised into broader change agents who combine IS and ICT skills with an understanding of the public sector context and of change management. African public sector managers need to be hybridised towards a broader skill set that includes an understanding of information systems and ICTs.

This clearly has extensive implications for training provision, since the development of hybrids will be critical to e-government success in Africa. Yet hybrid training in Africa is practically non-existent (Mundy et al 2001). Much of the current training supply for the public sector - both short professional programmes, and undergraduate and postgraduate programmes - is focused on technical tasks: the use of specific ICTs. As a result, there is too little provision of training covering the broader organisational processes of which ICTs are only one part. Thus the majority of training currently available does not help staff in African governments to engage effectively in the process of e-government-enabled reform.

These best practices may seem fairly straightforward. However, might they also represent Western designs that are inappropriate to African realities? To address this, 
we must draw out two problematic extreme views - stereotypes, even - that are undercurrents within a lot of debate about Africa, including e-government in Africa.

The first extreme view is: "Africa is the same as the West". There are some senses in which this can be supported. African nations suffer similar types of public sector problems. eGovernment is present in both Africa and the West, and suffers similar types of failure and similarly high rates of failure. Nonetheless, the central message of this paper has been that this extreme view is wrong. Its continuing presence leads to problems which arise when Western designs are transferred into African contexts: contexts which not the same, but which are different.

This has been seen to be true for e-government systems. As just asked, is it also true for e-government best practices? In the case of hybrids, the answer seems to be "no". Both survey research and training work in Africa have demonstrated the relevance of hybrids (Mundy et al. 2001). In the case of 'reality-legitimising' techniques such as soft systems and prototyping, the answer is less clear. Some have found them to work 'with the grain' of African realities (Korpela et al 1998); others have found them to be inappropriate (Braa and Hedberg 2000).

The second extreme view is: "Africa is completely different from the West".

Examples of differences have been given in this paper, but similarities have also emerged. Certainly, the notion that e-government in Africa is completely different from that in the West will be unwelcome. This can imply that e-government solutions for African nations must be custom-built from scratch; that models and lessons from the West have no place in Africa. Such implications would only serve to raise costs and cause delays.

This view can also imply the marginalisation of Africa in e-government debates, and the arrogant assumption that e-government experience, knowledge and ideas are a one-way traffic from the West to Africa. Ethically this should not be so.

Pragmatically, e-government in Africa is a valuable global experience base, for example in use of e-government to reach out to poor communities and to address social exclusion. Intellectually, as shown, e-government cases in Africa provide a 'stretch' between the contexts of design and implementation much greater than typically found in the West. This can supply insights into e-government that are harder to find in Western cases.

Thus, in discussing and conceptualising e-government in Africa, we must take care to steer between the stereotypes of similarity and difference.

Finally, in discussing stereotypes, we must equally beware one more undercurrent: "Africa is all the same". There are undoubted cultural, historical and geo-political similarities between many African nations, just as there are, for example, between Western European nations. Hence, there is some justification in continent-wide analysis. Nonetheless, there are also great differences, both between and within nations. Thus, e-government solutions that work in one country cannot simply be transplanted into a neighbouring country. The same respect for e-government differences accorded, say, to Germany and France should also be accorded, for example, to Nigeria and Cameroun or to Uganda and Tanzania. 


\section{References}

T.O. Adeboye, Governance and economic development, paper presented at Good Governance for Africa conference, Maastricht, 23-24 November, 1995.

Anonymous, Report on the Land Registry Computerisation Programme, PPM Programme, School of Oriental and African Studies, University of London, 2000.

G.B.N. Ayittey, Africa in Chaos, St Martins, New York, 1998.

A. Bada, A case study of IT and organizational change in a Nigerian bank, in: Information Flows, Local Improvisations and Work Practices, Proceedings of the IFIP WG9.4 Conference 2000, Cape Town, South Africa, 2000.

M. Barrett, S. Sahay and G. Walsham, Information technology and social transformation, The Information Society, 17(1) (2001), 5-20.

N. Baruah, Computerizing tax administration in India, in: Information Flows, Local Improvisations and Work Practices, Proceedings of the IFIP WG9.4 Conference 2000, Cape Town, South Africa, 2000.

A. Beeharry and G.M. Schneider, Creating a campus network culture in a newly developing economy, Information Technology for Development, 7(1) (1996), 3-16.

P. Benjamin, Community development and democratisation through information technology: building the new South Africa, in: Reinventing Government in the Information Age, R.B. Heeks, ed., Routledge, London, 2001, 194-210.

B.J. Berman and W.J. Tettey, African states, bureaucratic culture and computer fixes, Public Administration and Development, 21 (2001), 1-13.

J.A. Boon, Information and development, The Information Society, 8(4) (1992), 227 241.

J. Braa and C. Hedberg, Developing district-based health care information systems, in: Information Flows, Local Improvisations and Work Practices, Proceedings of the IFIP WG9.4 Conference 2000, Cape Town, South Africa, 2000.

Bridges.org, Comparison of E-Readiness Assessment Models, Bridges.org, Washington, DC, 2001.

R. Butler, Designing Organizations, Routledge, New York, 1991.

Cabinet Office, e-government: A Strategic Framework for Public Services in the Information Age, Central IT Unit, Cabinet Office, London, 2000.

http://www.iagchampions.gov.uk/Strategy.htm 
P. Cain, Automating personnel records for improved management of human resources: the experience of three African governments, in: Reinventing Government in the Information Age, R. Heeks, ed., Routledge, London, 2001, 135-155.

M. Castells, End of Millennium, $2^{\text {nd }}$ edn, Blackwell, Oxford, 2000.

P.B. Checkland, Systems Thinking, Systems Practice, Wiley, Chichester, UK, 1981.

P.B. Checkland and J. Scholes, Soft Systems Methodology in Action, Wiley, Chichester, UK, 1990.

CID, Readiness for the Networked World, Center for International Development, Harvard University, Cambridge, MA, 2000.

R. Common, The new public management and policy transfer, in: Beyond the New Public Management, M. Minogue, C. Polidano and D. Hulme, eds, Edward Elgar, Cheltenham, UK, 1998, 59-75.

W. Dodd and J. Fortune, An electronic patient record project in the United Kingdom: can it succeed?, in: Medinfo '95, R.A. Greenes, H.E. Peterson and D.J. Protti, eds, Healthcare Computing and Communications Canada, Edmonton, 1995, 301-304.

S. Garfinkel, A short history of digital signature legislation, in: Web Security, Privacy and Commerce, $2^{\text {nd }}$ edn, S. Garfinkel, ed., O'Reilly, Cambridge, MA, 2001.

M.S. Haque, The contextless nature of public administration in Third World countries, International Review of Administrative Sciences, 62(3) (1996), 315-329.

R.B. Heeks, Donors, development and ICTs: dazzle spots and blind spots, paper presented at DSA workshop on ICTs and Development, University of Manchester, 11 September, 2001.

R.B. Heeks, Building eGovernance for Development, iGovernment paper no.12, IDPM, University of Manchester, $2001 \mathrm{~b}$.

R.B. Heeks, Success and Failure Rates of eGovernment in Developing Countries, unpublished paper, IDPM, University of Manchester, 2002.

R.B. Heeks, eGovernment: An International Text on Public Sector Information Systems, Sage, London, forthcoming.

R.B. Heeks and C. Kenny, ICTs and development, in: ICTs and Development, Proceedings of the IFIP WG9.4 Conference 2002, S. Madon and S Krishna, eds, Bangalore, India, 2002, 29-44.

P. Henman, Does computerisation save governments money?, Information Infrastructure and Policy, 5 (1996), 235-251.

F.W. Horton and D. Lewis (eds), Great Information Disasters, ASLIB, London, 1991. 
ITU, World Telecommunications Report 2002, International Telecommunications Union, Geneva, 2002.

S. Kamel, Decision Support Systems and Strategic Public Sector Decision Making in Egypt, iGovernment paper no.3, IDPM, University of Manchester, 1998.

C. Kenny, The Internet and Economic Growth in LDCs, draft paper, World Bank, Washington, DC, 2001.

N. Korac-Kakabadse, A. Kouzmin and A. Korac-Kakabadse, Information technology and development, Public Administration and Development, 20 (2000), 171-184.

M. Korpela, H.A. Soriyan, K.C. Olufokunbi, A.A. Onayade, A. Davies-Adetugbo, and D. Adesanmi, Community participation in health informatics in Africa, Computer Support Cooperative Work, 7(3-4) (1998), 339-358.

A. Kruiter, Good Governance for Africa: Whose Governance?, ECDPM, Maastricht, 1996.

P.R. Lawrence and J.W. Lorsch, Organization and Environment, Harvard Press, Harvard, MA, 1967.

P. Lind, Computerization in Developing Countries: Model and Reality, Routledge, London, 1991.

B. Lollbeharree and R. Unuth, Contributions Network in Mauritius, World Bank, Washington, DC, 2001.

K.F. Matta and N.E. Boutros, Barriers to electronic mail systems in developing countries, The Information Society, 6(1-2) (1989), 59-68.

McConnell International, Risk E-Business: Seizing the Opportunity of Global EReadiness, McConnell International, Washington, DC, 2000.

Microsoft, IEC of South Africa wins Computerworld Smithsonian award, Government News, 28 June, Microsoft Europe, Reading, 2000.

M. Minogue, The internationalization of new public management, in: The Internationalization of Public Management, W. McCourt and M. Minogue, eds, Edward Elgar, Cheltenham, UK, 2001, 1-19.

R. Montealegre, A case for more case study research in the implementation of information technology in less-developed countries, Information Technology for Development, 8(4) (1999), 199-207.

A. Moussa and R. Schware, Informatics in Africa, World Development, 20(12) (1992), 1737-1752.

N.K. Mulira, Managing information technology in Uganda, Information Technology for Development, 6(2) (1995), 95-106. 
D. Mundy, C. Kanjo and P. Mtema, Meeting training needs for information age reform, in: Reinventing Government in the Information Age, R. Heeks, ed., Routledge, London, 2001, 271-292.

S. Ntiro, eGovernment in Eastern Africa, KPMG, Dar-es-Salaam, 2000.

M. Odedra-Straub, The role of international organisations in information technology transfer: the African experience, in: Technology and Developing Countries, R. Heeks, ed., Frank Cass, London, 215-224.

S.O. Ojo, Socio-cultural and organisational issues in IT applications in Nigeria, in: Social Implications of Computers in Developing Countries, S.C. Bhatnagar and M. Odedra, eds, Tata McGraw-Hill, New Delhi, 1992, 99-109.

B. Olowu, Redesigning African civil service reforms, Journal of Modern African Studies, 37 (1999), 1-23.

OMB, E-Government Strategy, Office of Management and Budget, Washington, DC, 2002.

G. Oyomno, Sustainability of governmental use of microcomputer-based information technology in Kenya, in: Global Information Technology and Socio-Economic Development, M. Odedra-Straub, ed., Ivy League Publishing, Nashua, NH, 1996, 1934.

PCIP, Roadmap for e-Government in the Developing World, Pacific Council for International Policy, Los Angeles, CA, 2002.

S.B. Peterson, Saints, demons, wizards and systems: why information technology reforms fail or underperform in public bureaucracies in Africa, Public Administration and Development, 18(1) (1998), 37-60.

A. Poulymenakou and A. Holmes, A contingency framework for the investigation of information systems failure, European Journal of Information Systems, 5 (1996), 3446.

Pyramid Research, Information Infrastructure Indicators 1990-2010, Pyramid Research, Boston, MA, 2000.

K. Raffer and H.W. Singer, The Foreign Aid Business, Edward Elgar, Cheltenham, UK, 1996.

A. Salazar, Evaluating information systems for decentralisation, in: Reinventing Government in the Information Age, R.B. Heeks, ed., Routledge, London, 2001, 156176.

C. Sauer, Why Information Systems Fail: A Case Study Approach, Alfred Waller, Henley, UK, 1993. 
C. Sauer, Deciding the future for IS failures: not the choice you might think, in: Rethinking Management Information Systems, R. Galliers and W.L. Currie, eds, Oxford University Press, Oxford, UK, 1999, 279-309.

T.N. Seyoum, Fisheries Scientific Information System, IDPM, University of Manchester, UK, 2002.

F. Teal, Private Sector Wages and Poverty in Ghana: 1988-1998, Centre for the Study of African Economies, University of Oxford, 2000.

W.J. Tettey, Transforming tax administration in Ghana, Development Policy Review, 15 (1997), 339-356.

W.J. Tettey, Computerization, institutional maturation and qualitative change. Information Technology for Development 9(2) (2000), 59-76.

O. Therkildsen, Public sector reform in a poor, aid-dependent country, Tanzania, Public Administration and Development, 20 (2000), 61-71.

G.J. Udo and F.M. Edoho, Information technology transfer to African nations, Journal of Technology Transfer, 25 (2000), 329-342.

D.M. West, WMRC Global E-Government Survey, Taubman Center for Public Policy, Brown University, Providence, RI, 2001.

G. Wilson and R.B. Heeks, Technology, poverty and development, in: Poverty and Development into the 21st Century, T. Allen and A. Thomas, eds, Oxford University Press, Oxford, 2000, 403-424.

E.E. Woherem, Information Technology in Africa, African Centre for Technology Studies, Nairobi, 1993.

J. Zammit, Report on the UNESCO Online Governance Survey Report, COMNET-IT, Blata I-Bajda, Malta, 2000. 